\title{
Dietary $n-3$ and $n-6$ fatty acids alter avian metabolism: molecular-species composition of breast-muscle phospholipids
}

\author{
Ronald E. Newman ${ }^{1,4}$, Wayne L. Bryden ${ }^{1,4}$, Eva Fleck ${ }^{2}$, John R. Ashes ${ }^{2}$, Leonard H. Storlien ${ }^{3,4}$ and \\ Jeffery A. Downing ${ }^{1,4}$ \\ ${ }^{1}$ Faculty of Veterinary Science, University of Sydney, Camden, NSW 2570, Australia \\ ${ }^{2}$ CSIRO Livestock Industries, Prospect, NSW, 2148, Australia \\ ${ }^{3}$ Department of Biomedical Sciences, University of Wollongong, NSW, 2522, Australia \\ ${ }^{4}$ Smart Food Centre, University of Wollongong, NSW 2522, Australia
}

(Received 30 August 2001 - Revised 11 January 2002 - Accepted 3 February 2002)

\begin{abstract}
The effects of diets high in $n-3$ polyunsaturated fatty acids (PUFA; provided by fish oil), $n-6$ PUFA (sunflower oil) or in more-saturated fatty acids (tallow) on the distribution of subclasses of choline phospholipids (PC) and ethanolamine phospholipids (PE) from the breast muscle of broiler chickens were examined. Supplementation with the different fatty acids had no effect on the distribution of phospholipid subclasses. Feeding sunflower oil or tallow gave a molecularspecies profile similar in both fatty acid subtype and proportion. In the diacyl PC phospholipids, $16: 0-18: 1 n-9$ and $16: 0-18: 2 n-6$ accounted for approximately $60 \%$ of the total molecular species, whereas for the alkylenyl PC the predominant species were $16: 0-18: 1 n-9$ and $16: 0-20: 4 n-6$. Of the diacyl PE the dominant species was $18: 0-20: 4 n-6$ which accounted for $50 \%$ of the molecular species, and of the alkylenyl PE the dominant species were $16: 0-18: 1 n-9,16: 0-20: 4 n-6$ and $18: 0-20: 4 n-6$. Supplementation with fish oil significantly increased levels of both eicosapentaenoic acid $(20: 5 n-3)$ and docosahexaenoic acid $(22: 6 n-3)$ in PC and PE when compared with either sunflower oil or tallow supplementation. The increase in the $n-3$ PUFA incorporation was associated with a corresponding decrease in the proportion of arachidonic acid $(20: 4 n-6)$ in both PC and PE. Different dietary fats induce different patterns of fatty acid incorporation and substitution in the $s n-2$ position of the diacyl and alkylenyl PC and PE of avian breast muscle, and this finding is indicative of selective acyl remodelling in these two phospholipids.
\end{abstract}

Chicken: Ethanolamine phospholipids: Choline phospholipids: Polyunsaturated fatty acids

Cell membranes modulate a variety of cellular functions, including receptor-mediated signal transduction, the processing of receptor ligand complexes, the passage of hydrophobic effectors such as steroid hormones that interact with their cytoplasmic membrane receptors, and the passage and transport of ions and nutrients (Birnbaumer et al. 1977; Robertson, 1983; Steinman et al. 1983; Hulbert \& Else, 2000); factors critical to normal cellular function. Although membrane composition and functional properties are regulated by genetic and environmental components, it has become increasingly clear that membrane lipids, particularly the fatty acyl chains play a key role in determining cellular function (see Hulbert \& Else, 1999).
Diet is a major environmental factor, and alteration of the dietary fatty acid profile affects several physiological processes, including the lowering of plasma lipid concentrations, modulation of eicosanoid formation and cell membrane properties (Harris, 1989; Kinsella et al. 1990). Although $n$-3 polyunsaturated fatty acids (PUFA) have received greater attention because of their perceived health benefits, consumption of $n-6$ PUFA, specifically linoleic acid (18:2n-6; LA), also modulates metabolism by reducing lipid secretion (Strum-Odin et al. 1987) and enhancing both insulin binding and insulin action (Field et al. 1990; Cheema et al. 1992). Fatty acids such as eicosapenaenoic acid (20:5n-3; EPA), docosahexaenoic acid

Abbreviations: AA, arachidonic acid (20:4); DHA, docosahexaenoic acid (22:6); EPA, eicosapentaenoic acid (20:5); LA, linoleic acid (18:2); PC, choline phospholipids; PE, ethanolamine phospholipids; PUFA, polyunsaturated fatty acid.

* Corresponding author: Dr Ron Newman, fax +61 24655 0693, email ronaldn@camden.usyd.edu.au 
(22:6n-3; DHA) and arachidonic acid (20:4n-6; AA) are absorbed and incorporated into the subclasses (diacyl and alkylenyl) of phospholipids containing choline (PC) and ethanolamine (PE) in muscle of ruminants (Scott et al. 1993) and single-stomached animals (dogs; Gross, 1985)

The dietary fat profile has also been implicated in modulating the body fat content of chickens (Sanz et al. 2000; Newman et al. 2002), rodents (Cunnane et al. 1986; Shimomura et al. 1990; Cheema et al. 1992) and man (Couet et al. 1997). The feeding of specific fat types influences the composition of body-weight gain. For example, feeding $n$-3 PUFA reduces body-weight gain in genetically-obese ob/ob mice (Cunnane et al. 1986), while dietary n-6 PUFA reduce body fat in rats (Shimomura et al. 1990), and diets high in saturated fatty acids lead to an increase in body fatness when compared with highly-enriched PUFA diets (Shimomura et al. 1990; Pan et al. 1994). These responses correspond to changes in tissue phospholipidfatty acid composition that reflect the dietary fatty acid profile (Pan \& Storlien, 1993). Changes in phospholipid composition may alter the physical and chemical dynamics of the cell membrane (Clandinin et al. 1991), and this change may inturn influence processes involved in energy metabolism.

Newman et al. (2002) demonstrated that dietary fat source (fish oil, sunflower oil or tallow) alters abdominal fat deposition and intermediary metabolism in broiler chickens. A reduction in body fat content occurred when the dietary fat was predominately PUFA. In view of the relationship between dietary fatty acids, tissue phospholipids and body composition (Pan \& Storlien, 1993), we characterised the major molecular species of PC and PE subclasses (diacyl and alkylenyl; Scott et al. 1993; Schmid et al. 1995; Hermier et al. 1999) in breast muscle samples obtained from birds fed fish oil, sunflower oil and tallow according to Newman et al. (2002), to determine the form of remodelling that occurs when feeding different sources of PUFA.

\section{Materials and methods}

Birds, diets and study design

Details of the experimental design, diets and birds, including management and collection of samples have been described by Newman et al. (2002). The diets contained $80 \mathrm{~g}$ edible grade tallow $(<1 \%(\mathrm{w} / \mathrm{w})$ free fatty acids), sunflower oil or fish oil $/ \mathrm{kg}$ and were fed to the chickens from age 3 to 8 weeks. The fatty acid composition of the three experimental diets is shown in Table 1. The breast muscle tissue for molecular-species analysis was obtained from four broiler chickens fed each of the experimental diets.

\section{Material}

Phospholipase C (Bacillus cerus type XIII), benzoic anhydride, and 4-dimethylaminopyridine were purchased from Sigma Chemical Co. (St Louis, MO, USA). Phospholipids and diacylglycerol standards were obtained from Serdary (London, Ont., Canada). TLC plates, silica gel 60F 254
Table 1. Fatty acid composition ( $\mathrm{g} / 100 \mathrm{~g}$ ) of the experimental diets*

\begin{tabular}{|c|c|c|c|}
\hline Fatty acid & Fish oil & Sunflower oil & Tallow \\
\hline $14: 0$ & $5 \cdot 17$ & ND & 1.04 \\
\hline $16: 0$ & $16 \cdot 03$ & 8.55 & $25 \cdot 24$ \\
\hline $16: 1$ & 6.03 & ND & $1 \cdot 12$ \\
\hline $18: 0$ & 3.43 & $4 \cdot 31$ & 6.06 \\
\hline $18: 1$ cis 9 & $14 \cdot 07$ & $23 \cdot 27$ & 38.03 \\
\hline $18: 2 n-6$ & $19 \cdot 77$ & 62.73 & $25 \cdot 80$ \\
\hline $18: 3 n-3$ & 1.81 & $1 \cdot 13$ & 1.49 \\
\hline $20: 0$ & 2.94 & ND & ND \\
\hline $20: 5 n-3$ & $13 \cdot 41$ & ND & ND \\
\hline $22: 6 n-3$ & $8 \cdot 77$ & ND & ND \\
\hline Total saturated (S) & $27 \cdot 6$ & $12 \cdot 9$ & $32 \cdot 3$ \\
\hline Total monounsaturated & 24.94 & $23 \cdot 27$ & $39 \cdot 15$ \\
\hline Total polyunsaturated $(P): n-6$ & $19 \cdot 77$ & $62 \cdot 73$ & $25 \cdot 80$ \\
\hline$n-3$ & 23.59 & $1 \cdot 13$ & 1.47 \\
\hline $\mathrm{P}: \mathrm{S} \dagger$ & 1.57 & 4.97 & 0.84 \\
\hline
\end{tabular}

$\mathrm{ND}$, not detected.

${ }^{*}$ For details of diets, see Newman et al. (2002).

$\dagger n-6+n-3 / 14: 0+16: 0+18: 0+20: 0$.

$(200 \mathrm{~mm} \times 200 \mathrm{~mm})$, were obtained from E. Merck (Darmstadt, Germany). The solvents used for the TLC solvent system were AR grade and those for HPLC separation were HPLC grade, and they were supplied by Mallinckrodt, Selby Biolab (Sydney, NSW, Australia).

\section{Lipid extraction}

Total lipids were extracted from $10 \mathrm{~g}$ muscle tissue with chloroform-methanol $(2: 1, \mathrm{v} / \mathrm{v})$ containing $0.01 \%(\mathrm{v} / \mathrm{v})$ butylated hydroxytoluene. The tissue was macerated for 2 min using a Waring blender, equilibrated for $4 \mathrm{~h}$ at room temperature then filtered (Watman no. 1 filter paper). The filtrate was washed with water (Folch et al. 1957) and the phases allowed to separate before aspirating and discarding the top phase. The bottom layer was retained, evaporated to dryness and redissolved in chloroform-methanol $(2: 1, \mathrm{v} / \mathrm{v})$.

\section{Separation of phospholipids and neutral lipids}

Glass columns $(20 \mathrm{ml})$ were prepared by loading with $3-$ $5 \mathrm{~g}$ silicic acid suspended in $10-15 \mathrm{ml}$ chloroform. The lipid samples were dissolved in chloroform $(0.5 \mathrm{ml})$, applied to the top of the column and then eluted with $60 \mathrm{ml}$ chloroform to separate the neutral lipids. The phospholipids were then eluted with $60 \mathrm{ml}$ methanol and their concentration was determined from $\mathrm{P}$ estimation using a factor of $\mathrm{P} \times 25$ (Bartlett, 1959).

\section{Separation of total phospholipids into individual phospholipid classes}

All remaining phospholipid extracts were evaporated to dryness and then redissolved in 100-200 $\mu$ l chloroformmethanol $(2: 1, \mathrm{v} / \mathrm{v})$. Samples and phospholipid standards were separated by TLC using silica gel $G$ plates that had been activated by incubating at $100^{\circ} \mathrm{C}$ for $1 \mathrm{~h}$. The plates were then run in solvent system no. $1(60 \mathrm{ml}$ chloroform - $25 \mathrm{ml}$ methanol $-50 \mathrm{ml}$ acetone $-2 \mathrm{ml}$ acetic acid - 
$5 \mathrm{ml}$ water), air-dried for 20-30 min and then dried under vacuum for $30 \mathrm{~min}$. The silica plates were then run in the same direction in solvent system no. $2(60 \mathrm{ml}$ chloroform - $50 \mathrm{ml}$ methanol $-10 \mathrm{ml}$ acetic acid $-3.3 \mathrm{ml}$ water). Individual phospholipids and standards were initially visualised by spraying the plates with ninhydrin, incubating at $100^{\circ} \mathrm{C}$ and then re-spraying to detect $\mathrm{P}$ (Vaskovsky et al. 1975). Final visualisation of the lipids was achieved by spraying the plate with 2,7-dichlorofluorescein $(0.02 \%(\mathrm{w} / \mathrm{v})$ in ethanol) and then exposing it to u.v. light. Areas of gel corresponding to the phospholipids were scraped off the plate and extracted with chloroform-methanol-water $(5: 5: 1$, by vol.). The phospholipid extracts were washed three times in water and the volumes were adjusted to $10 \mathrm{ml}$ with chloroform-methanol $(2: 1, \mathrm{v} / \mathrm{v})$. A portion of the extract was used to prepare fatty acid methyl esters (Christie, 1989) and these derivatives were separated and quantified using GLC (Perkin Elmer Autosystem, FID and PE Nelson data processing system, model 10202, Perkin Elmer Pty Ltd., CT, USA), fitted with a BPX 70 capillary column $(50 \mathrm{~mm} \times 0.25 \mathrm{~mm})$ SGE Australia Pty Ltd, Ringwood, Victoria, Australia). He was used as the carrier gas with an injection split ratio of $100: 1$. The GLC was temperature programmed from $150^{\circ} \mathrm{C}$ to $210^{\circ} \mathrm{C}$ at a rate of $2^{\circ} \mathrm{C} \mathrm{min}$, with an injection temperature of $210^{\circ} \mathrm{C}$ and a detector temperature of $250^{\circ} \mathrm{C}$. Peaks separated were identified by comparison with standard samples of known composition. A portion of the phospholipid extract was used to determine the amount of phospholipid-P and the remainder was used for analysis of molecular species.

\section{Separation of molecular species}

The purified phospholipids were evaporated to dryness, redissolved in $10 \mathrm{~mm}$-Tris hydrochloride $(\mathrm{pH} \mathrm{7.5}$; $1.25 \mathrm{ml}$ ) containing $30 \mathrm{~mm}-\mathrm{H}_{3} \mathrm{BO}_{3}$ and $10 \mathrm{~mm}-\mathrm{CaCl}_{2}$ then sonicated in a cold water bath $\left(2^{\circ} \mathrm{C}\right)$ for $5 \mathrm{~min}$. Individual phospholipids $(1-2 \mathrm{mg})$ were hydrolysed with 50 units phospholipase $\mathrm{C}$, then extracted with $2 \mathrm{ml}$ diethyl ether, mixed by vortexing and incubated overnight at room temperature, while being constantly agitated. The diethyl ether layer was removed and the released 1,2-diacylglycerols were extracted in diethyl ether and dried under $\mathrm{N}_{2}$ (Blank et al. 1984).

\section{Benzoate derivatives}

The extracted and dried diacylglycerols were dissolved in $0.3 \mathrm{ml}$ benzene containing benzoic anhydride $(10 \mathrm{mg})$ and 4-dimethylaminopyridine $(4 \mathrm{mg})$ and allowed to react for $2 \mathrm{~h}$. The benzoate derivatives were extracted three times with $2 \mathrm{ml}$ hexane and separated into three subclasses (diacyl, alkylacyl and alkylenyl) by TLC on silica gel G in a solvent system of toluene-hexane-diethyl ether $(50: 45: 5$, by vol.). The diacylglycerolbenzoates were visualised under u.v. light and the areas of gel corresponding to these derivatives were scraped from the plates and extracted with hexane. The diacylglycerol extract was evaporated to dryness, and the diacylglycerol redissolved in acetronitrile-2-propanol $(80: 20, \mathrm{v} / \mathrm{v})$, and the distribution of the three subclasses in the PE and PC was determined by measuring the absorbance at $230 \mathrm{~nm}$.

\section{Separation by HPLC}

The molecular species of the diacyl and alkylenyl derivatives were separated using a Waters (Milford, CT, USA) HPLC system, comprising a 501 pump, a 484 u.v. detector (operating at $230 \mathrm{~nm}$ ), and a 740 data module. An SGE ODS $2-8 / 5$ column $(5 \mu \mathrm{m}, 250 \mathrm{~mm} \times 4 \mathrm{~mm}$ i.d.; SGE Australia Pty Ltd) was used at an operating temperature of $24^{\circ} \mathrm{C}$. Samples of the benzoate derivatives were positioned using two solvent systems, acetonitrile-2-propanol $(80: 20, \mathrm{v} / \mathrm{v})$ and methanol-2-propanol $(95: 5$, v/v). The molecular species were separated by isocratic elution at a flow rate of 1.0 and $0.8 \mathrm{ml} / \mathrm{min}$ respectively. A $12: 0-$ 12:0 diacylglycerolbenzoate derivative was used as an internal standard.

\section{Identification of molecular species}

Identification of the individual molecular species was achieved by a combination of HPLC analysis of standards, plotting their relative retention times using the methods outlined by Takamura et al. (1986), Bell (1989) and Takamura \& Kito (1991), and GLC analysis of the fatty acid methyl esters of the peaks corresponding to the eluted species.

\section{Results}

Distribution of choline phospholipid subclasses in muscle

The percentage distribution of the PC subclasses (diacyl, alkylacyl and alkylenyl) for the three dietary treatments is shown in Fig. 1(a). The diacyl subclass accounted for the highest percentage of the PC fraction. The feeding of the different dietary fats had no significant effect on the distribution of the PC subclasses. For birds fed the fish oil diet the diacyl subclass comprised 81.8 (SE 2.9) $\%$ and for the sunflower oil- and tallow-fed chickens the corresponding values were 78.9 (SE 1.8) and 76.8 (SE 2.5) \% respectively. The percentage distributions of the alkylacyl and alkylenyl subclass for the three dietary groups were respectively, 6.7 (SE 0.9) and 11.5 (SE 3.1) for the fish oil group, 7.71 (SE 0.6) and 13.5 (SE 1.9) for the sunflower oil group and 6.9 (SE 0.7) and 16.3 (SE 1.9) for the tallow group.

\section{Distribution of ethanolamine phospholipid subclasses in muscle}

The percentage distribution of the PE subclasses (diacyl, alkylacyl and alkylenyl) for the three dietary treatments is shown in Fig. 1(b). As for the PC subclasses, the feeding of the dietary fats had no significant effect on the distribution of the PE subclasses. However, unlike those for the PC subclasses the percentage distributions for the PE diacyl and the alkylenyl subclasses were similar. Feeding fish oil to chickens resulted in a percentage distribution of 49.2 (SE 14.9) and 46.1 (SE 15.9) for the diacyl and 

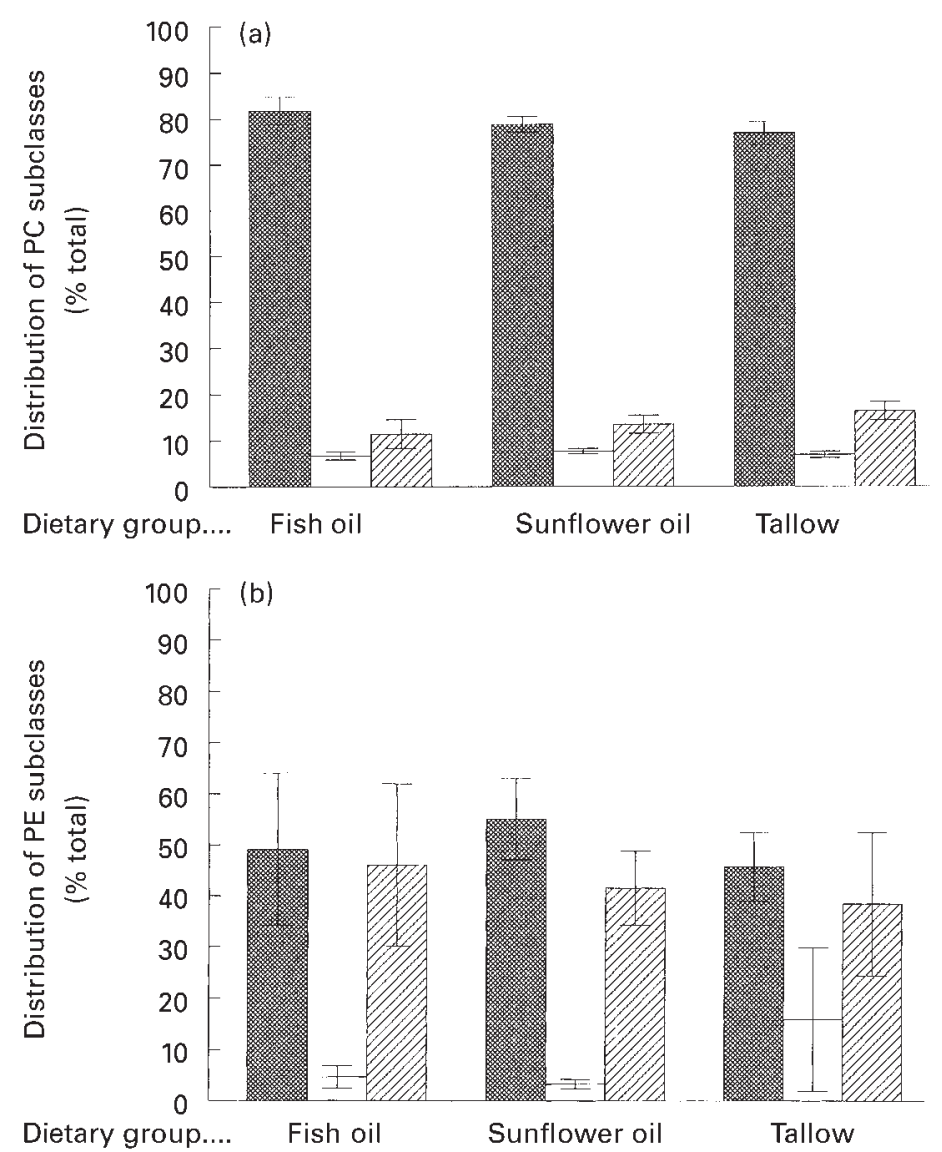

Fig. 1. Distribution of (a) choline phospholipid (PC) subclasses and (b) ethanolamine phospholipid (PE) subclasses (diacyl (ख) alkylacyl ( $\square$ ) and alkylenyl (晌) in breast muscle from chickens fed fish oil, sunflower oil or tallow. For details of diets and procedures, see p. 20. Values are means with their standard errors represented by vertical bars.

alkylenyl subclasses respectively. Similarly, the percentage distributions for the diacyl and alkylenyl subclasses were respectively 55.2 (SE 8.0) and 41.5 (SE 7.3) for the sunflower oil group and 45.7 (SE 6.8) and 38.4 (SE 14.1) for the tallow group. The alkylacyl subclass was present at a significantly lower $(P<0 \cdot 01)$ level with all dietary treatments when compared with both the diacyl and alkylenyl subclasses.

\section{Molecular species composition}

Choline phospholipid diacyl subclass. The composition of the molecular species of the PC diacyl subclass for breast muscle is shown in Table 2. The predominant molecular species observed were 16:0-18:1n-9 and 16:0$18: 2 n-6$. For the fish oil, sunflower oil and tallow groups these two species accounted for (\%) 37.2 (SE 3.9) and 13.7 (SE 1.2), 30.45 (SE 6.7) and 27.3 (SE 2.2) and 40.6 (SE 5.1) and 28.8 (SE 5.1) \% respectively. The percentage of $16: 0-18: 1$ was similar for all three dietary treatments. However, 16:0-18:2 was significantly reduced $(P<0 \cdot 01)$ in the muscle from birds fed fish oil when compared with that from birds fed either sunflower oil or tallow. Fish oil feeding resulted in a sixteenfold increase in the percentage of $16: 0-20: 5 n-3(7.9(\mathrm{SE} 2.7))$ and a fivefold increase in that of $16: 0-22: 6 n-3(11 \cdot 1(\mathrm{sE} 2 \cdot 0))$ when compared with chickens fed the sunflower oil diet, and this increase was slightly greater than that for chickens fed tallow. The increased concentrations of $20: 5 n-3$ and $22: 6 n-3$ in the fish oil-fed chickens were associated with a corresponding decrease in the concentration of 20:4n-6 (Fig. 2(a)). Although the percentages and concentrations of the molecular species for sunflower oil-and tallow-fed chickens were similar, the molecular species 16:0-20:4 and 18:0-20:4 were significantly $(P<0 \cdot 05)$ elevated in the sunflower oil-fed chickens when compared with tallowfed chickens. Feeding sunflower oil resulted in an increase in the molecular species containing two or more double bonds and a proportional decrease in molecular species containing one double bond when compared with tallowfed chickens.

Choline phospholipid alkylenyl subclass. The composition of the molecular species for the PC alkylenyl subclass for the three dietary treatments is given in Table 3 . The predominant molecular species in the muscle of birds fed the sunflower oil and tallow diets were 16:0$18: 1 n-9$ and $16: 0-20: 4 n-6$. However, for chickens fed fish oil the predominant species was $16: 0-22: 6 n-3$. In addition, there was a significant decrease $(P<0.01)$ in the concentration of $16: 0-18: 1$ in the PC of fish oil-fed 
Table 2. Comparison of the molecular species of the choline phospholipid diacyl subclass $(\mathrm{mol} / 100 \mathrm{~mol})$ in breast muscle from chickens fed fish oil-, sunflower oil- or tallow-supplemented diets*

(Values are means with their standard errors for duplicate analysis of samples from four birds)

\begin{tabular}{|c|c|c|c|c|c|c|}
\hline \multirow{2}{*}{$\begin{array}{l}\text { Dietary group... } \\
\text { Molecular species }\end{array}$} & \multicolumn{2}{|c|}{ Fish oil } & \multicolumn{2}{|c|}{ Sunflower oil } & \multicolumn{2}{|c|}{ Tallow } \\
\hline & Mean & SE & Mean & SE & Mean & SE \\
\hline $18: 1-20: 5$ & $0.47^{\mathrm{a}}$ & 0.18 & $0.09^{b}$ & 0.05 & $0.06^{b}$ & 0.02 \\
\hline $16: 0-20: 5$ & $7 \cdot 91^{\mathrm{a}}$ & 2.66 & $0.48^{\mathrm{b}}$ & 0.60 & $0.27^{b}$ & 0.09 \\
\hline $16: 0-22: 6$ & $11 \cdot 05^{\mathrm{a}}$ & $2 \cdot 01$ & $1.98^{\mathrm{b}}$ & 0.75 & $0.98^{\mathrm{C}}$ & 0.19 \\
\hline $18: 1-22: 5$ & $0.58^{\mathrm{a}}$ & 0.02 & $0.22^{b}$ & 0.04 & $0.38^{a b}$ & 0.17 \\
\hline $18: 1-20: 4$ & ND & & 0.33 & $0 \cdot 15$ & 0.34 & 0.06 \\
\hline $16: 0-22: 5$ & $3.40^{\mathrm{a}}$ & 0.39 & $1.92^{b}$ & $0 \cdot 86$ & $1 \cdot 16^{\mathrm{b}}$ & 0.30 \\
\hline $16: 0-20: 4$ & $3 \cdot 11^{\mathrm{a}}$ & 0.37 & $8 \cdot 43^{\mathrm{b}}$ & $2 \cdot 29$ & $5 \cdot 34^{c}$ & $1 \cdot 17$ \\
\hline $18: 0-20: 5$ & $2.39^{\mathrm{a}}$ & 0.34 & $0.75^{\mathrm{b}}$ & 0.31 & $0.35^{\mathrm{C}}$ & 0.09 \\
\hline $18: 1-18: 2$ & 0.62 & 0.43 & 1.56 & 0.25 & 1.72 & 0.47 \\
\hline $18: 0-22: 6$ & ND & & ND & & $2 \cdot 23$ & 0.26 \\
\hline $16: 0-18: 2$ & $13 \cdot 73^{\mathrm{a}}$ & $1 \cdot 22$ & $27 \cdot 28^{b}$ & $2 \cdot 24$ & $28 \cdot 81^{b}$ & 5.08 \\
\hline $18: 0-22: 5$ & $1.45^{\mathrm{a}}$ & 0.37 & $0.72^{b}$ & 0.34 & $0.39^{b}$ & 0.02 \\
\hline $18: 0-20: 4$ & $1.25^{\mathrm{a}}$ & 0.55 & $3.92^{b}$ & 0.72 & $2 \cdot 65^{\mathrm{C}}$ & 0.39 \\
\hline $18: 0-16: 1$ & 0.55 & 0.08 & ND & & ND & \\
\hline $18: 1-18: 1$ & $1 \cdot 20$ & 0.48 & 1.50 & 0.44 & $2 \cdot 13$ & 0.49 \\
\hline $18: 0-18: 2$ & $3.89^{a}$ & 1.11 & $9 \cdot 53^{b}$ & 2.94 & $6 \cdot 94^{\mathrm{b}}$ & 1.11 \\
\hline $16: 0-18: 1$ & $37 \cdot 18$ & 3.90 & $30 \cdot 45$ & $6 \cdot 66$ & $40 \cdot 45$ & $5 \cdot 14$ \\
\hline $18: 0-22: 4$ & $2 \cdot 83$ & 0.75 & 3.07 & 1.23 & 2.33 & 0.84 \\
\hline $18: 0-18: 1$ & 3.35 & 0.75 & 3.39 & 0.63 & $3 \cdot 27$ & 0.39 \\
\hline $18: 0-16: 0$ & 0.43 & 0.13 & 0.94 & 0.76 & 0.37 & 0.14 \\
\hline Total & $95 \cdot 39$ & & $96 \cdot 55$ & & $100 \cdot 06$ & \\
\hline
\end{tabular}

ND, not detected.

a,b,c Mean values in the same row with unlike superscript letters were significantly different (ANOVA; $P<0.05)$.

${ }^{*}$ For details of diets and procedures, see p. 20.

chickens when compared with that of sunflower oil-and tallow-fed groups (18.6 SE 3.6, 26.9 SE 5.1 and $34.6 \mathrm{SE}$ $7.8 \%$ respectively). Conversely, the percentage of 16:0$22: 6$ for the fish oil group was increased sixfold when compared with that for the sunflower oil group and ninefold when compared with that for the tallow group (39.1 (SE 4.3) 6.4 (SE 0.1) and 4.1 (SE 1.1) \% respectively). As was detected in the PC diacyl subclass, fish oil feeding also increased the percentage of $16: 0-20: 5 n-3$; a tenfold increase when compared with that for the sunflower oil group and a ninefold increase when compared with that for the tallow group. The increased concentrations of $20: 5 n-3$ and $22: 6 n-3$ were associated with a decrease in $20: 4 n-6$ (Fig. 2(b)), as was shown for the diacyl subclass. The feeding of sunflower oil, a diet high in $n-6$ PUFA, resulted in a molecular-species profile containing individual fatty acids at similar percentages to those in the profile of chickens fed tallow. However, as observed in the diacyl subclass, the sunflower oil diet increased fatty acids that contained two or more double bonds and decreased species containing one double bond when compared with tallowfed chickens.

Ethanolamine phospholipid diacyl subclass. The molecular species profile for the PE diacyl subclass is shown in Table 4. As observed for the PC subclasses, the molecular-species profile and their percentages were similar for both the tallow-and sunflower oil-fed chickens. However, the predominant species of the PE diacyl subclass was 18:0-20:4 for the sunflower oil-and tallow-fed chickens, and accounted for 51.1 and $46.3 \%$ respectively. With fish oil feeding the predominant molecular species were $18: 0-20: 5$ and $18: 0-22: 6$, accounting for $21 \cdot 3$ and $29.1 \%$ respectively. These percentages were significantly higher $(P<0 \cdot 01)$ than those found in muscle from birds offered the sunflower oil or the tallow diets. As for the PC, fish oil feeding increased the concentration of the long-chain PUFA, $20: 5 n-3$ and $22: 6 n-3$, and significantly reduced $(P<0 \cdot 01)$ the concentration of $20: 4 n-6$ when compared with the sunflower oil-and tallow-fed chickens (Fig. 2(c)).

Ethanolamine phospholipid alkylenyl subclass. The distribution of molecular species in the alkylenyl PE subclass for the three dietary groups is shown in Table 5. The feeding of sunflower oil and tallow resulted in profiles that were similar in species type and concentration. The dominant molecular species observed for these dietary groups were $16: 0-18: 1,16: 0-20: 4$ and $18: 0-20: 4$, accounting for $17.9,10.7$ and $14.1 \%$ respectively for the sunflower oil-fed chickens and 24.1, 12.7 and $10.9 \%$ respectively for the tallow-fed group. The dominant fatty acid species for the fish oil-fed chickens were 16:0$22: 6$ and 18:0-22:6, and these molecular species accounted for 40.1 and $18.9 \%$ of the alkylenyl PE subclass respectively. Consistent with the observations for the other phospholipid subclasses, the feeding of fish oil significantly increased $(P<0.01)$ the proportion of the $n-3$ species 16:0-22:6 and 18:0-22:6 and significantly decreased $(P<0 \cdot 01)$ the percentage of $16: 0-20: 4$ and $18: 0-20: 4$ (Fig. 2(d)) compared with both sunflower oil-and tallowfed chickens. 
Table 3. Comparison of the molecular species of the choline phospholipid alkylenyl subclass $(\mathrm{mol} / 100 \mathrm{~mol})$ in breast muscle from chickens fed fish oil-, sunflower oilor tallow-supplemented diets*

(Values are means with their standard errors for duplicate analyses of samples from four birds)

\begin{tabular}{|c|c|c|c|c|c|c|}
\hline \multirow{2}{*}{$\begin{array}{l}\text { Dietary group... } \\
\text { Molecular species }\end{array}$} & \multicolumn{2}{|c|}{ Fish oil } & \multicolumn{2}{|c|}{ Sunflower oil } & \multicolumn{2}{|c|}{ Tallow } \\
\hline & Mean & SE & Mean & SE & Mean & SE \\
\hline $16: 1-20: 4$ & 0.24 & $0 \cdot 10$ & 0.40 & 0.29 & 0.12 & 0.05 \\
\hline $18: 1-20: 5$ & $1.28^{\mathrm{a}}$ & 0.45 & $0.64^{\mathrm{b}}$ & 0.14 & $0.44^{c}$ & 0.07 \\
\hline $16: 0-20: 5$ & $9 \cdot 50^{\mathrm{a}}$ & 4.86 & $0.92^{b}$ & 0.71 & $1.02^{\mathrm{b}}$ & 0.41 \\
\hline $18: 1-22: 6$ & $3 \cdot 80^{\mathrm{a}}$ & 0.19 & $1.05^{\mathrm{b}}$ & 0.65 & $0.36^{\mathrm{b}}$ & 0.14 \\
\hline $16: 0-22: 6$ & $39 \cdot 13^{\mathrm{a}}$ & $4 \cdot 31$ & $6 \cdot 39^{b}$ & 2.51 & $4 \cdot 10^{b}$ & $1 \cdot 10$ \\
\hline $18: 1-22: 5$ & $0.93^{\mathrm{a}}$ & 0.07 & $0.61^{b}$ & 0.05 & $0.42^{b}$ & 0.18 \\
\hline $18: 1-20: 4$ & ND & & 8.05 & 1.92 & 6.46 & 1.85 \\
\hline $16: 0-22: 5$ & 4.99 & 0.36 & ND & & ND & \\
\hline $16: 0-20: 4$ & $6 \cdot 47^{\mathrm{a}}$ & 1.48 & $24 \cdot 39^{b}$ & 3.25 & $22 \cdot 69^{b}$ & 3.61 \\
\hline $18: 0-20: 5$ & $1.25^{\mathrm{a}}$ & 0.40 & $2 \cdot 21^{\mathrm{b}}$ & 0.51 & $1.94^{\mathrm{ab}}$ & 0.41 \\
\hline $18: 1-18: 2$ & ND & & $3.48^{\mathrm{a}}$ & 0.83 & $1 \cdot 89^{b}$ & 0.33 \\
\hline $18: 0-22: 6$ & $4 \cdot 22^{\mathrm{a}}$ & 1.08 & $1.05^{\mathrm{b}}$ & 0.12 & $0.78^{\mathrm{C}}$ & 0.15 \\
\hline $16: 0-18: 2$ & $1.87^{\mathrm{a}}$ & 0.12 & $4 \cdot 12^{b}$ & 0.56 & $6 \cdot 77^{\mathrm{C}}$ & 1.99 \\
\hline $16: 0-22: 4$ & ND & & $5 \cdot 06$ & 0.90 & $5 \cdot 85$ & 1.00 \\
\hline $18: 0-22: 5$ & 0.33 & 0.05 & 0.76 & 0.39 & ND & \\
\hline $18: 0-20: 4$ & $1.83^{a}$ & 0.60 & $5 \cdot 86^{b}$ & 0.87 & $4.04^{\mathrm{C}}$ & 0.41 \\
\hline $18: 1-18: 1$ & $1.44^{\mathrm{a}}$ & 0.37 & $3 \cdot 28^{b}$ & 0.70 & $3 \cdot 15^{\mathrm{b}}$ & 0.55 \\
\hline $16: 0-18: 1$ & $18 \cdot 55^{\mathrm{a}}$ & 3.57 & $26 \cdot 95^{\mathrm{b}}$ & 5.07 & $34.58^{b}$ & $7 \cdot 76$ \\
\hline $18: 0-18: 2$ & $1 \cdot 10$ & 0.40 & 1.75 & 0.41 & 1.59 & 0.40 \\
\hline $18: 0-22: 4$ & $0.71^{\mathrm{a}}$ & 0.33 & $0.93^{a b}$ & 0.47 & $1 \cdot 35^{\mathrm{b}}$ & 0.29 \\
\hline $18: 0-18: 1$ & $0.62^{a}$ & 0.37 & $1 \cdot 21^{\mathrm{b}}$ & 0.26 & $0.79^{\mathrm{ab}}$ & 0.23 \\
\hline $18: 0-16: 0$ & 0.09 & 0.05 & 0.11 & 0.07 & & \\
\hline Total & 98.33 & & $99 \cdot 22$ & & $98 \cdot 31$ & \\
\hline
\end{tabular}

ND, not detected

$\mathrm{a}, \mathrm{b}, \mathrm{c}$ Mean values in the same row with unlike superscript letters were significantly different (ANOVA; $P<0.05)$.

${ }^{*}$ For details of diets and procedures, see p. 20.

Table 4. Comparison of the molecular species of the ethanolamine phospholipid diacyl subclass $(\mathrm{mol} / 100 \mathrm{~mol})$ in breast muscle from chickens fed fish oil-, sunflower oil- or tallow-supplemented diets*

(Values are means with their standard errors for duplicate analyses of samples from four birds)

\begin{tabular}{|c|c|c|c|c|c|c|}
\hline \multirow{2}{*}{$\begin{array}{l}\text { Dietary group... } \\
\text { Molecular species }\end{array}$} & \multicolumn{2}{|c|}{ Fish oil } & \multicolumn{2}{|c|}{ Sunflower oil } & \multicolumn{2}{|c|}{ Tallow } \\
\hline & Mean & SE & Mean & SE & Mean & SE \\
\hline $18: 1-20: 5$ & $1.45^{\mathrm{a}}$ & 0.51 & ND & & $0.25^{b}$ & 0.12 \\
\hline $16: 0-20: 5$ & $3 \cdot 91^{a}$ & 0.47 & $0.50^{b}$ & 0.22 & $0.45^{\mathrm{b}}$ & 0.11 \\
\hline $16: 0-22: 6$ & $7 \cdot 01^{a}$ & 1.05 & $1.66^{\mathrm{b}}$ & 0.15 & $1.53^{b}$ & 0.32 \\
\hline $18: 1-20: 4$ & 0.73 & 0.32 & 0.51 & 0.14 & 0.55 & 0.19 \\
\hline $16: 0-22: 5$ & $1.23^{\mathrm{a}}$ & 0.16 & $1 \cdot 36^{\mathrm{ab}}$ & 0.49 & $2.09^{b}$ & 0.67 \\
\hline $16: 0-20: 4$ & $1 \cdot 71^{\mathrm{a}}$ & 0.40 & $5 \cdot 65^{b}$ & 0.93 & $7 \cdot 30^{c}$ & 0.46 \\
\hline $18: 0-20: 5$ & $21 \cdot 31^{a}$ & $5 \cdot 19$ & $1 \cdot 73^{b}$ & 0.87 & $1.79^{b}$ & 0.12 \\
\hline $18: 1-18: 2$ & 1.90 & 0.47 & ND & & ND & \\
\hline $18: 0-22: 6$ & $29 \cdot 09^{\mathrm{a}}$ & 7.59 & $5 \cdot 48^{\mathrm{b}}$ & 1.33 & $4 \cdot 05^{\mathrm{b}}$ & 0.25 \\
\hline $16: 0-18: 2$ & $1 \cdot 70^{\mathrm{a}}$ & 0.32 & $4 \cdot 37^{b}$ & 0.83 & $5 \cdot 92^{b}$ & 1.46 \\
\hline $18: 0-22: 5$ & $3.04^{a}$ & 0.77 & $1 \cdot 11^{\mathrm{b}}$ & 0.30 & $0.67^{\mathrm{c}}$ & 0.03 \\
\hline $18: 0-20: 4$ & $10 \cdot 25^{\mathrm{a}}$ & 0.42 & $51.09^{b}$ & $2 \cdot 34$ & $46 \cdot 25^{\mathrm{b}}$ & $5 \cdot 21$ \\
\hline $18: 0-16: 1$ & $0.62^{\mathrm{a}}$ & 0.36 & $3 \cdot 20^{b}$ & 0.73 & $1.93^{\mathrm{C}}$ & 0.37 \\
\hline $18: 1-18: 1$ & 0.74 & 0.07 & 0.65 & 0.49 & 1.02 & 0.27 \\
\hline $18: 0-18: 2$ & $5 \cdot 16^{\mathrm{a}}$ & 0.90 & $5 \cdot 01^{a}$ & 0.86 & $8 \cdot 23^{b}$ & 0.55 \\
\hline $16: 0-18: 1$ & $4 \cdot 80^{a}$ & 0.59 & $12 \cdot 89^{b}$ & 1.62 & $12 \cdot 20^{\mathrm{b}}$ & 3.47 \\
\hline $18: 0-22: 4$ & 0.20 & 0.11 & $0 \cdot 18$ & 0.04 & ND & \\
\hline $18: 0-18: 1$ & $4 \cdot 09^{a}$ & 0.67 & $2 \cdot 39^{b}$ & 0.28 & $3 \cdot 86^{\mathrm{a}}$ & 0.61 \\
\hline $18: 0-16: 0$ & 0.13 & 0.08 & $0 \cdot 20$ & 0.08 & 0.21 & 0.06 \\
\hline Total & $99 \cdot 81$ & & 97.98 & & $98 \cdot 30$ & \\
\hline
\end{tabular}

ND, not detected.

$\mathrm{a}, \mathrm{b}, \mathrm{c}$ Mean values in the same row with unlike superscript letters were significantly different (ANOVA; $P<0.05$ ).

${ }^{*}$ For details of diets and procedures, see p. 20. 

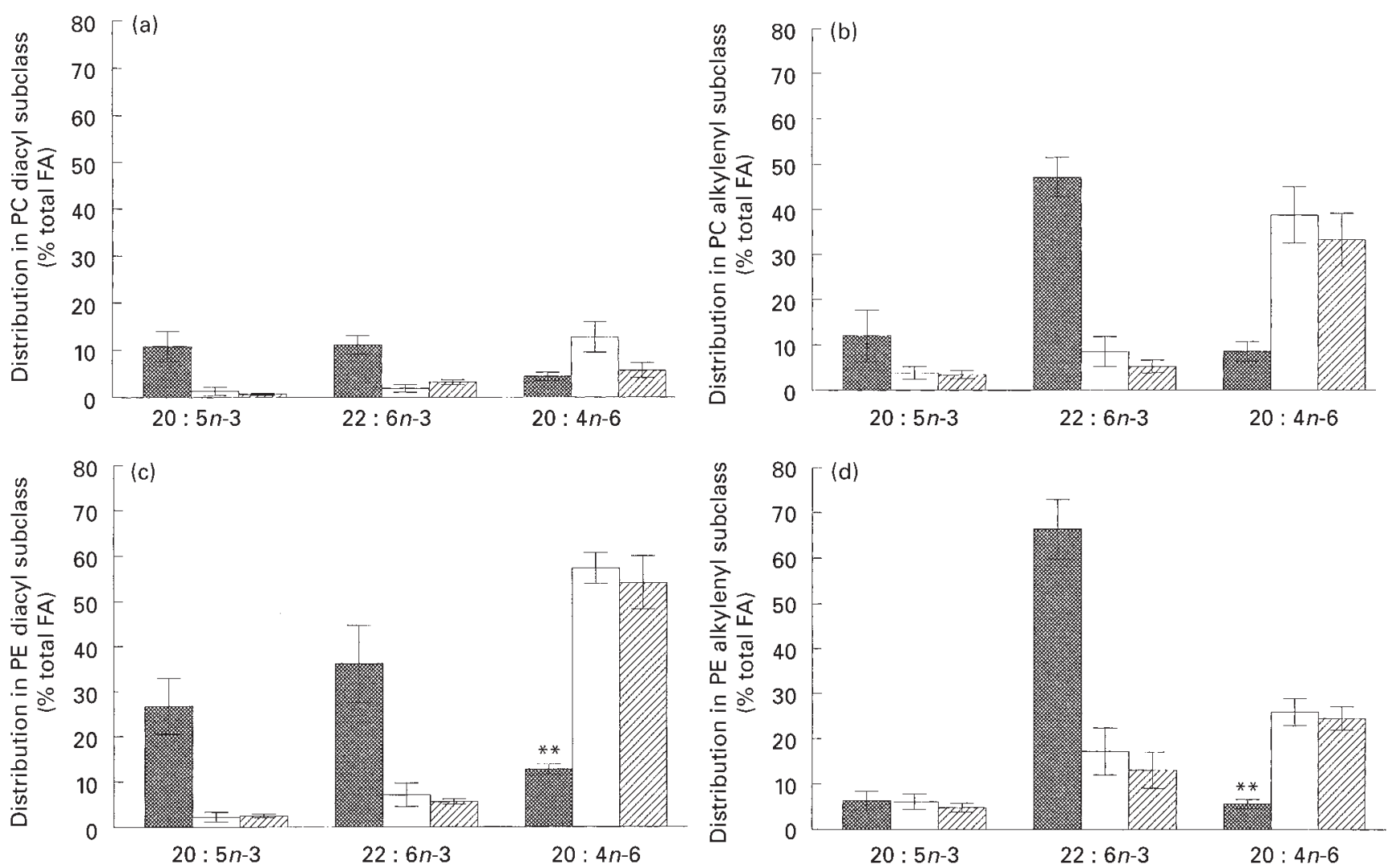

Fig. 2. Distribution of eicosapentaenoic acid of $(20: 5 n-3)$, docosahexaenoic acid $(22: 6 n-3)$ and arachidonic acid (20:4n-6) in the choline phospholipid (PC) diacyl (a) and alkylenyl (b) subclasses and in the ethanolamine phospholipid (PE) diacyl (c) and alkylenyl (d) subclasses in breast muscle from chickens fed fish oil $(\otimes)$, sunflower oil $(\square)$ or tallow (四). FA, fatty acids. For details of diets and procedures see p. 20. Values are means with their standard errors represented by vertical bars. Mean values were significantly different from those for the other two diets: ${ }^{* *} P<0.01$.

\section{Discussion}

The present study demonstrates that the fatty acid molecularspecies profile of avian breast-muscle phospholipids reflects the composition of dietary fat. Feeding fish oil to chickens increased the total content of long-chain PUFA, EPA $(20: 5 n-3)$ and DHA (22:6n-3) from the $n$-3 series, in all subclasses of PC and PE. Feeding of sunflower oil, high in LA $(18: 2 n-6)$, increased the content of the $n-6$ PUFA LA and AA $(20: 4 n-6)$ in the phospholipid subclasses. Interestingly, the profiles of PC and PE and their subclasses in birds fed tallow were similar to those of birds fed sunflower oil, even though the concentration of LA in the tallow diet was $60 \%$ less than that in the sunflower oil diet. The samples used for this study were taken from birds described in the previous paper (Newman et al. 2002). In that study it was demonstrated that birds fed fish and sunflower oil had a significantly reduced abdominal fat pad mass $(P<0.01)$ and lower plasma triacylglycerol levels compared with birds fed tallow. However, examination of the present data clearly shows that the remodelling of the molecular species that occurred in response to the dietary fat profile was similar for broilers fed sunflower oil and tallow, but different for those fed fish oil. The present results suggest that the changes in fat deposition and energy metabolism noted for the three dietary groups (Newman et al. 2002) are not related to membrane $\mathrm{PE}$ and $\mathrm{PC}$ composition. This finding does not discount the possibility that other membrane components may be involved in the physiological changes observed.

Hazel \& Williams (1990) and Schmid et al. (1995) suggested that the membrane bilayer is regulated to maintain a relatively constant physical state, referred to as 'homeoviscous' adaptation. This process could simply provide the cell membrane with a uniform fatty acyl environment. Individual phospholipids have the potential to 'gel out' at different temperatures, which can cause phase separation, resulting in a membrane environment consisting of solid gel patches, while other phospholipids remain in the liquid crystalline phase (Schroeder et al. 1998). Our results support the classical physiological structure, with the $s n-1$ positions occupied by a saturated fatty acid and the $s n-2$ positions occupied by an unsaturated fatty acid. This form of 'compulsory mixing' has been suggested by Hulbert \& Else (1999) as a means of limiting phase separation in natural membranes.

In other avian species the major tissue phospholipids are PC and PE. In both Landes and Poland geese PC accounts for approximately $70 \%$ of the total phospholipid and PE accounts for approximately $25 \%$ of the total phospholipid (Hermier et al. 1999). The predominance of PE and PC as the major phospholipids also occurs in mammals (Schmid et al. 1995). Membrane studies using cultured murine 
Table 5. Comparison of the molecular species of the ethanolamine phospholipid alkylenyl subclass $(\mathrm{mol} / 100 \mathrm{~mol})$ in breast muscle from chickens fed fish oil-, sunflower oil- or tallow-supplemented diets*

(Values are means with their standard errors for duplicate analyses of samples from four birds)

\begin{tabular}{|c|c|c|c|c|c|c|}
\hline \multirow{2}{*}{$\begin{array}{l}\text { Dietary group... } \\
\text { Molecular species }\end{array}$} & \multicolumn{2}{|c|}{ Fish oil } & \multicolumn{2}{|c|}{ Sunflower oil } & \multicolumn{2}{|c|}{ Tallow } \\
\hline & Mean & SE & Mean & SE & Mean & SE \\
\hline $16: 1-20: 4$ & $0 \cdot 12^{a}$ & 0.03 & $0 \cdot 10^{a}$ & 0.02 & $0.06^{b}$ & 0.01 \\
\hline $18: 1-20: 5$ & $0.78^{a}$ & 0.18 & $0.95^{\mathrm{a}}$ & 0.20 & $0.44^{\mathrm{b}}$ & 0.08 \\
\hline $16: 0-20: 5$ & $3.04^{a}$ & 1.21 & $2 \cdot 30^{\mathrm{a}}$ & 0.80 & $0.92^{b}$ & 0.24 \\
\hline $18: 1-22: 6$ & $6 \cdot 44^{\mathrm{a}}$ & 2.46 & $1.43^{\mathrm{b}}$ & 0.67 & $1.79^{b}$ & 0.46 \\
\hline $16: 0-22: 6$ & $40 \cdot 99^{a}$ & 1.89 & $9 \cdot 35^{\mathrm{b}}$ & 1.92 & $7 \cdot 88^{\mathrm{b}}$ & 0.99 \\
\hline $18: 1-20: 4$ & $1.47^{\mathrm{a}}$ & 0.25 & $1.03^{b}$ & 0.02 & $0.83^{\mathrm{C}}$ & 0.14 \\
\hline $16: 0-22: 5$ & $3 \cdot 63^{\mathrm{a}}$ & 0.22 & $7 \cdot 87^{b}$ & 0.57 & $8 \cdot 39^{b}$ & 1.04 \\
\hline $16: 0-20: 4$ & $2 \cdot 30^{\mathrm{a}}$ & 0.34 & $10 \cdot 71^{\mathrm{b}}$ & 0.99 & $12 \cdot 73^{\mathrm{c}}$ & 0.74 \\
\hline $18: 0-20: 5$ & $2 \cdot 80$ & 0.66 & $2 \cdot 87$ & 0.69 & 3.40 & 0.72 \\
\hline $18: 1-18: 2$ & ND & & 3.53 & 0.54 & $3 \cdot 14$ & 0.99 \\
\hline $18: 0-22: 6$ & $18 \cdot 94^{\mathrm{a}}$ & $2 \cdot 16$ & $6 \cdot 40^{\mathrm{b}}$ & $2 \cdot 65$ & $3.44^{\mathrm{b}}$ & $2 \cdot 58$ \\
\hline $16: 0-18: 2$ & $0.68^{a}$ & 0.22 & $1.78^{b}$ & 0.51 & $1 \cdot 24^{b}$ & 0.32 \\
\hline $16: 0-22: 4$ & ND & & $6 \cdot 22$ & $1 \cdot 20$ & $7 \cdot 22$ & $1 \cdot 20$ \\
\hline $18: 0-22: 5$ & $1.51^{\mathrm{a}}$ & 0.29 & $2 \cdot 26^{\mathrm{b}}$ & 0.57 & $1.94^{\mathrm{b}}$ & 0.31 \\
\hline $18: 0-20: 4$ & $1.68^{a}$ & 0.38 & $14.08^{b}$ & $2 \cdot 01$ & $10 \cdot 92^{c}$ & 1.66 \\
\hline $18: 1-18: 1$ & $1 \cdot 10^{\mathrm{a}}$ & 0.22 & $3 \cdot 12^{b}$ & 0.89 & $3 \cdot 88^{b}$ & 0.16 \\
\hline $16: 0-18: 1$ & $10 \cdot 22^{a}$ & $3 \cdot 19$ & $17 \cdot 88^{\mathrm{b}}$ & 3.06 & $24 \cdot 11^{\mathrm{c}}$ & 3.77 \\
\hline $18: 0-18: 2$ & $0.78^{a}$ & 0.21 & $2 \cdot 63^{b}$ & 0.50 & $2 \cdot 71^{\mathrm{b}}$ & 0.59 \\
\hline $18: 0-22: 4$ & $0.37^{a}$ & 0.08 & $0 \cdot 10^{\mathrm{b}}$ & 0.05 & $0.90^{b}$ & 0.04 \\
\hline $18: 0-18: 1$ & $1 \cdot 11^{\mathrm{a}}$ & 0.26 & $2 \cdot 67^{b}$ & 0.25 & $3 \cdot 13^{\mathrm{b}}$ & 0.40 \\
\hline $18: 0-16: 0$ & 0.12 & 0.11 & ND & & ND & \\
\hline Total & 98.08 & & $97 \cdot 25$ & & $99 \cdot 05$ & \\
\hline
\end{tabular}

ND, not detected.

$a, b, c$ Mean values in the same row with unlike superscript letters were significantly different (ANOVA; $P<0.05$ ).

${ }^{*}$ For details of diets and procedures, see p. 20.

neuroblastoma cells have shown that fatty acids are rapidly incorporated and esterified into phospholipids, and that the rate of incorporation into $\mathrm{PC}$ is more rapid when compared with that of other phospholipids (Chakravarthy et al. 1986).

In the present study, LA, EPA and DHA were the principal fatty acids that paired predominantly with a 16:0 in PC, whereas AA, EPA and DHA were the principal fatty acids that were paired predominantly with 18:0 in PE. Studies in rats have shown that EPA and DHA have a high affinity for acylation to the $s n-2$ position of plasmalogen phospholipids (Blank et al. 1989, 1994). In addition, AA has also been shown to occur in a high proportion at the $s n-2$ position of the molecular species of diacyl PE from ruminant (Scott et al. 1993) and chicken (Blank et al. 1992) muscle. The concentration of fatty acids of the $n-3$ and $n-6$ series incorporated into the phospholipids was reflective of the dietary fatty acid concentration. Chickens fed fish oil displayed a greater proportion of EPA and DHA than AA in both PC and PE of the breast muscle. For chickens fed sunflower oil and tallow diets there was a greater proportion of LA and AA. This finding is consistent with those of other studies in chickens which show increased levels of EPA and DHA in the spermatozoan phospholipids after 30 weeks of fish oil supplementation (Kelso et al. 1997) and a corresponding decrease in $n-6$ fatty acids, specifically LA and AA. Similar results have also been reported in mammals; when rats were fed fish oil there was an increase in the concentrations of both EPA and DHA in the ethanolamine plasmalogens, while the movement of AA between the lipid classes was impassed (Blank et al. 1994).

The $n-3$ fatty acids EPA and DHA seem to preferentially displace LA rather than oleic acid (18:1n-9) from the $s n-2$ position in the diacyl subclass of PC. In the alkylenyl subclass of PC, oleic acid and LA were displaced by EPA and DHA. Scott et al. (1993) have reported a similar substitution for oleic acid in ruminants fed fish oil; however, this substitution occurred only in the PC diacyl subclass. From the present study there is evidence of specificity of $n-3$ and $n-6$ fatty acids for different PE and PC subclasses. Concentrations of LA and AA were greater in the diacyl subclasses for both PE and PC, whereas the concentrations of EPA and DHA were found to be greater in the alkylenyl subclasses of both phospholipids.

The current study also suggests that both EPA and DHA are remodelled between the PE and PC. Remodelling of phospholipid molecular species has been shown to involve the deacylation-reacylation pathways from the combined actions of phospholipases and acyltransferases, and transacylases (Blasinde et al. 1995). Both EPA and DHA are present as a high proportion in the PE and PC. The high concentration of these two species is likely to be due to the dietary intake, as vertebrates are only capable of synthesising de novo saturated and monounsaturated chains (Hulbert \& Else, 2000). Schmid et al. (1995) report that only a limited number of molecular species of PC and PE are remodelled by deacylation-reacylation at either the $s n-1$ or $s n-2$ position of glycerol; included 
among this number is DHA. Other studies indicate that PCDHA can be formed from the specific methylation of PEDHA (Vance, 1988; Samborski et al. 1993).

The major essential fatty acid for poultry is LA, and it is important for chick growth, egg production and egg size (Balnave, 1970; Watkins, 1991). Our results suggest that the $n-3$ series PUFA may also be important, as both EPA and DHA were incorporated to a significant extent into the breast-muscle phospholipids of chickens fed all dietary treatments. Interestingly, EPA and DHA were not present in the dietary fatty acid profile of either the sunflower oil or tallow diets. While these diets did contain a small concentration of $\alpha$-linolenic acid (18:3n-3), it comprised only $1.5 \%$ of the total dietary lipid. The EPA and DHA of the phospholipids from birds on these treatments was presumably synthesised from $\alpha$-linolenic acid through the sequence of alternating desaturation and chain-elongation reactions (Cook, 1991). The finding that both these fatty acid series were present in the membranes of all chickens regardless of the dietary fat type underscores their importance as an essential requirement for poultry diets.

In summary, we have shown that the $n-3$ and $n-6$ longchain PUFA are preferentially assimilated into the membrane phospholipids of chicken breast muscle. Although dietary $n-3$ and $n$-6 PUFA induce similar physiological outcomes (Cunnane et al. 1986; Shimomura et al. 1990; Sanz et al. 2000; Newman et al. 2002), the present study indicates that this result is not reflected in the remodelling of the molecular species of the major phospholipid classes. Further studies are required to elucidate the mechanism(s) that alter energy metabolism initiated by these dietary fatty acids.

\section{Acknowledgements}

The authors are grateful to the Australian Rural Industries Research and Development Corporation, Chicken Meat Committee for financial support and to R. P. Scherer Holdings Pty Ltd, Victoria, Australia who supplied the fish oil for the experimental diets. The authors would also like to thank Dr T. W. Scott for valuable discussions during the course of these studies.

\section{References}

Balnave D (1970) Essential fatty acids in poultry nutrition. World's Poultry Science Journal 26, 442-449.

Bartlett GR (1959) Phosphorus assay in column chromatography. Journal of Biological Chemistry 234, 466-471.

Bell MV (1989) Molecular species analysis of phosphoglycerides from ripe roes of cod (Gadus morhua). Lipids 24, 585-588.

Birnbaumer L, Duran JM, Nakahara T \& Kaumann AJ Mammalian Cell Membranes, vol. 5, pp. 105-150 [GA Jamieson and DM Robinson, editors]. Toronto, Ont.: Butterworths.

Blank ML, Cress EA, Smith ZL \& Snyder F (1992) Meats and fish consumed in the American diet contain substantial amounts of ether-linked phospholipids. Journal of Nutrition 122, 1656-1661.

Blank ML, Robinson M, Fitzgerald V \& Snyder F (1984) Novel quantitative method for determination of molecular species of phospholipids and diglycerides. Journal of Chromatography 298, 473-482.
Blank ML, Smith ZL, Cress EA \& Snyder F (1994) Molecular species of ethanolamine plasmalogens and transacylase activity in rat tissues are altered by fish oil diets. Biochimica et Biophysica Acta 1214, 295-302.

Blank ML, Smith ZL, Lee YJ \& Snyder F (1989) Effects of eicosapentaenoic and docosahexaenoic acid supplements on phospholipid composition and plasmalogen biosynthesis in P388DI cells. Archives of Biochemistry and Biophysics 269, 603-611.

Blasinde J, Bianco ID, Ackermann EJ, Conde-Frieboes K \& Dennis EA (1995) Inhibition of calcium-independent phospholipase $\mathrm{A}_{2}$ prevents arachidonic acid incorporation and phospholipid remodelling in $\mathrm{P}_{388} 8 \mathrm{D}_{1}$ macrophages. Proceedings of the National Academy of Sciences USA 92, 8527-8531.

Chakravarthy BR, Spence MW \& Cook HW (1986) Turnover of phospholipid fatty acyl chains in cultured neuroblastoma cells: involvement of deacylation-reacylation and de novo synthesis in plasma membranes. Biochimica et Biophysica Acta 879, 264-277.

Cheema SK, Venkatraman J \& Clandinin MT (1992) Insulin binding to liver nuclei from lean and obese mice is altered by dietary fat. Biochimica et Biophysica Acta 1117, 37-41.

Christie WW (1989) Gas Chromatography and Lipids - A Practical Guide. Ayr, South Ayrshire: Oily Press.

Clandinin MT, Cheema S, Field CJ, Garg ML, Vendatraman J \& Clandinin TR (1991) Dietary fat: exogenous determination of membrane structure and cell function. FASEB Journal 5, $2761-2769$.

Cook HW (1991) Fatty acid desaturation and chain elongation in eukaryotes. In Biochemistry of Lipids, Lipoproteins and Membranes, pp. 141-169 [DE Vance and J Vance, editors]. Amsterdam: Elsevier.

Couet C, Delarue J, Ritz P, Antoine J-M \& Lamisse F (1997) Effect of dietary fish oil on body fat mass and basal oxidation in healthy adults. International Journal of Obesity 21, 637-643.

Cunnane SC, McAdoo KR \& Horrobin DF (1986) Essential fatty acids decrease weight gain in genetically obese mice. British Journal of Nutrition 56, 87-89.

Field CJ, Edmond AR, Thompson ABR \& Clandinin MT (1990) Diet fat composition alters membrane phospholipid composition, insulin binding, and glucose metabolism in adipocytes from control and diabetic animals. Journal of Biological Chemistry 19, 11143-11150.

Folch J, Lees M \& Sloane-Stanley GH (1957) A simple method for the isolation and purification of total lipids from animal tissues. Journal of Biological Chemistry 226, 497-509.

Gross RW (1985) Identification of plasmalogen as the major phospholipid constituent of sarcoplasmic reticulum. Biochemistry 24, 1662-1668.

Harris WS (1989) Fish oils and plasma lipid and lipoprotein metabolism in humans: A critical review. Journal of Lipid Research 30, 785-807.

Hazel JR \& Williams EE (1990) The role of alterations in membrane lipid composition in enabling physiological adaptation of organisms to their physical environment. Progress in Lipid Research 29, 167-227.

Hermier D, Salichon MR, Guy G \& Peresson R (1999) Differential channelling of liver lipids in relation to susceptibility to hepatic steatosis in the goose. Poultry Science 78, 1398-1406.

Hulbert AJ \& Else PL (1999) Membranes as possible pacemakers of metabolism. Journal of Theoretical Biology 199, 257-274.

Hulbert AJ \& Else PL (2000) Mechanisms underlying the cost of living in animals. Annual Reviews of Physiology 62, 207-235.

Kelso KA, Cerolini S, Noble RC, Sparks NHC \& Speake BK (1997) The effects of dietary supplementation with docosahexaenoic acid on the phospholipid fatty acid composition of 
avian spermatozoa. Comparative Biochemistry and Physiology 118B, 65-69.

Kinsella JE, Lokesh B \& Stone RA (1990) Dietary $n-3$ polyunsaturated fatty acids and amelioration of cardiovascular disease: possible mechanisms. American Journal of Clinical Nutrition 52, 1-28.

Newman RE, Bryden WL, Fleck E, Ashes JR, Buttemer WA, Storlien LH \& Downing JA (2002) Dietary n-3 and n-6 fatty acids alter avian metabolism: metabolism and abdominal fat deposition. British Journal of Nutrition 88, 11-18.

Pan DA, Hulbert AJ \& Storlien LH (1994) Dietary fats, membrane phospholipids and obesity. Journal of Nutrition 124, 1555-1565.

Pan DA \& Storlien LH (1993) Dietary lipid profile is a determinant of tissue phospholipid fatty acid composition and rate of weight gain in rats. Journal of Nutrition 123, 512-519.

Robertson RN (1983) The Lively Membranes. Cambridge: Cambridge University Press.

Samborski RW, Ridgway ND \& Vance DE (1993) Metabolism of molecular species of phosphatidylethanolamine and phosphatidylcholine in rat hepatocytes during prolonged inhibition of phosphatidylethanolamine $\mathrm{N}$-methyltransferase. Journal of Lipid Research 34, 125-137.

Sanz M, Lopez-Bote CJ, Menoyo D \& Bautista JM (2000) Abdominal fat deposition and fatty acid synthesis are lower and $\beta$-oxidation is higher in broiler chickens fed diets containing unsaturated rather than saturated fat. Journal of Nutrition 130, 3034-3037.

Schmid PC, Deli E \& Schmid HHO (1995) Generation and remodelling of phospholipid molecular species in rat hepatocytes. Archives of Biochemistry and Biophysics 319, 168-176.

Schroeder F, Wood WG \& Kier AB (1998) The biological membrane and lipid domains. In Cell Physiology Source Book, 2nd ed., pp. 61-74 [N Sperelekis, editor]. San Diego, CA: Academic Press.

Scott TW, Ashes JR, Fleck E \& Gulati SK (1993) Effect of fish oil supplementation on the composition of molecular species of choline and ethanolamine glycerophospholipids in ruminant muscle. Journal of Lipid Research 34, 827-835.

Shimomura Y, Tamura T \& Suzuki M (1990) Less body fat accumulation in rats fed a sunflower oil diet than in rats fed a beef tallow diet. Journal of Nutrition 120, 1291-1296.

Steinman RM, Mellman IS, Muller WA \& Cohn ZA (1983) Endocytosis and the recycling of plasma membranes. Journal of Cell Biology 96, 1-27.

Strum-Odin R, Adkins-Finke B, Blake WL, Phinney SD \& Clarke SD (1987) Modification of fatty acid composition of membrane phospholipid in hepatocyte monolayer with $n-3, n-6$ and $n-9$ fatty acids and its relationship to triacylglycerol production. Biochimica et Biophysica Acta 921, 378-391.

Takamura H \& Kito M (1991) A highly sensitive method for quantitative analysis of phospholipid molecular species by high-performance liquid chromatography. Journal of Biochemistry 109, 436-439.

Takamura H, Narita H, Urade R \& Kito M (1986) Quantitative analysis of polyenoic phospholipid molecular species by high performance liquid chromatography. Lipids 21, 356-361.

Vance JE (1988) Compartmentalization and differential labelling of phospholipids of rat liver subcellular membranes. Biochimica et Biophysica Acta 963, 10-20.

Vaskovsky VE, Kostetsky EY \& Vasendin IM (1975) A universal reagent for phospholipid analysis. Journal of Chromatography 114, 129-141.

Watkins BA (1991) Importance of essential fatty acids and their derivatives in poultry. Journal of Nutrition 121, 1475-1485. 